\title{
ANIMATED INFOGRAPHICS AS A POTENTIAL TOOL IN VISUAL ART PEDAGOGY
}

\author{
Nene Tei-Narh ${ }^{1}$ and William Kwabena Nantwi ${ }^{2}$ \\ ${ }^{1}$ Faculty of Applied Art, Accra Technical University, Accra, Ghana. \\ ${ }^{2}$ Department of Creative arts, Offinso College of Education, Offinso, Ghana \\ Correspondence: ${ }^{1}$ teinarhnene@gmail.com ${ }^{2}$ williamnantwi28@gmail.com
}

Cite this article:

Nene T., William K.N. (2022), Animated Infographics as A Potential Tool in Visual Art Pedagogy. British Journal of Contemporary Education 2(1), 1-16. DOI: 10.52589/BJCEZQIZRNOY.

\section{Manuscript History}

Received: 20 Dec 2021

Accepted: 12 Jan 2021

Published: 22 Jan 2022

Copyright $\odot 2020$ The Author(s). This is an Open Access article distributed under the terms of Creative Commons AttributionNonCommercial-NoDerivatives 4.0 International (CC BY-NC-ND 4.0 ), which permits anyone to share, use, reproduce and redistribute in any medium, provided the original author and source are credited.
ABSTRACT: The study adopted a qualitative approach with the case study to ascertain the pedagogical environment and infographics format(s) used by Visual Art teachers in the teaching and learning of Visual Art subjects in Senior High Schools. Respondents for the study were sampled purposively and conveniently from KNUST Senior High School, Kumasi, Ghana. Findings from the study indicated the non-availability of animated infographics as an instructional tool in the Visual Art classroom and the inefficiency of instructional delivery with only textbooks. For better comprehension and achievement of instructional objectives, the study recommended animated infographics as an alternative pedagogical strategy to the conventional way of instruction in the Visual Art classroom.

KEYWORDS: Infographics, Pedagogy, Visual Literacy, Instructional Design \& Technology, 


\section{INTRODUCTION}

Considering numerous researches (DeGraft-Yankson, 2010; Siaw 2009; Siaw \& Nortey, 2011; Evans-Solomon, 2004; Evans-Solomon \& Opoku-Asare, 2011; Opoku-Asare, Agbenatoe \& deGraft-Johnson, 2014) conducted in Visual Art Education especially in a typical Ghanaian context, it is refreshing to note that none of these studies considers the pedagogical environment that informs how Visual Art subjects are taught. Although DeGraft-Yankson's (2010) study looked at the integration of Information and Communication Technologies (ICTs) into the Ghanaian Senior High School Visual art curriculum, the study was alien to the pedagogical environment and infographics format(s) adopted by Visual Art teachers in the teaching and learning of Visual Art subjects.

Elsewhere, Science, Technology, Engineering and Mathematics (STEM) researchers (Shafer, 1996; Coleman, 2010; Noh and Son, 2015; Hassan, 2016; Shafipoor, Sarayloo \& Shafipoor, 2016; Warmann, 2016), have demonstrated that infographics could be an auxiliary tool that supports the cognitive comprehension of instructional content. Despite the fascinating impact and endorsement by these educational researchers in STEM, little is known of the potential and impact of teaching and learning with infographics in the Visual Art classroom.

It is against this background that this study sought to examine the format(s) of infographics used in the teaching and learning of Visual Art subjects and the effectiveness of the available infographic formats adopted in providing instructional content to Visual Art students. The research was undertaken at KNUST Senior High School in the Kumasi Metropolis in the Ashanti region of Ghana considering its proximity to the researchers and because it falls within the category of grade A schools in Ghana.

\section{The Purpose of the Study}

The purpose of the study was to identify and discuss the effects of available infographic format(s) used in the teaching and learning of Visual Art subjects in Senior High Schools using KNUST Senior High School as the case.

\section{LITERATURE REVIEW}

\section{Infographics}

As a means of communicating with one another, cavemen and women drew pictures on walls and rocks. This can be traced as far back as 3,500 years. Despite the gradual and periodical shift in the use of pictures to communicate from the Paleolithic period of man's settlement, it would not be out of place to submit that pictures still rule. From pictograms that characterize cave art to Egyptian hieroglyphics to ideograms on modern signs, humans have been drawing to communicate.

A popular visual approach to deliver abstract, complex and dense in technologically advancing global village has seen the use of infographics as a mediating tool (Lamb, Polman, Newman \& Smith, 2014; Smiciklas, 2012; Vanichvasin, 2013). Infographics as a concept originate from information literacy, which entails a "set of skills needed to find, decode and use information" (American Library Association 1996-2013). It consists of two words "info" and "graphic". 


\section{Towards A Working Definition}

Several theories suggest that early paintings of animals and hunting scenes by the cave artists were not just religious or decorative, but connote a way of communication. This has, however, been the bedrock of infographics: communicating information.

Several professionals and researchers have attempted a definition for the term "infographics" (Al-Mohammadi, 2017; Hassan, 2016; Y1ldırım, 2016; Smiciklas, 2012; Arum 2012). This study adopts the definition of infographics as the presentation of information within a certain flow by using visuals and texts. Infographics help convey complex or abstract information to the target audience in a more comprehensive manner.

Other terms such as data visualization, information design, or information architecture are associated with the process of infographics creation and publishing.

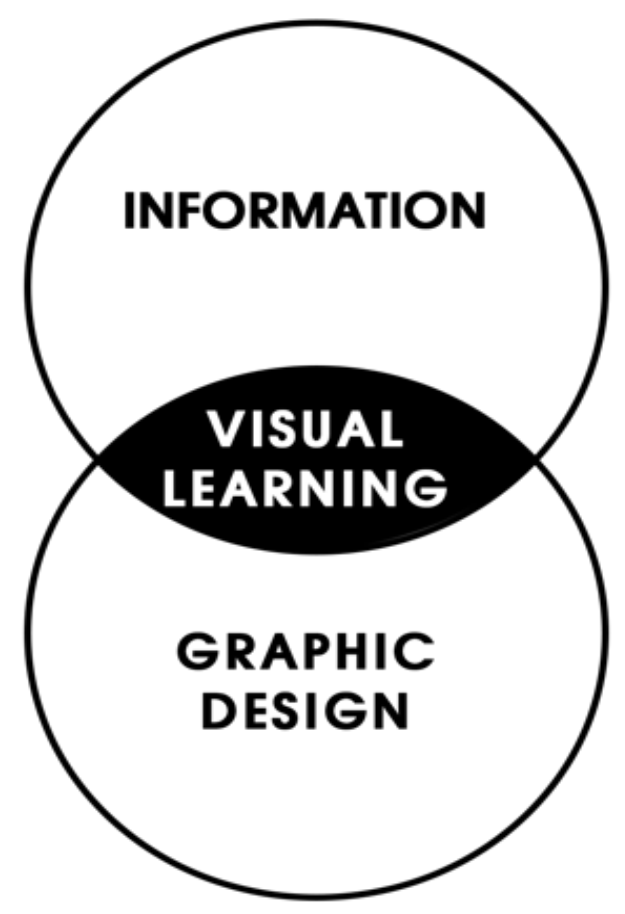

Figure 1. Anatomy of an infographic

Source: Smiciklas (2012)

Infographics is basically composed of three parts: visual, content and knowledge (Roy, 2009). The visual aspect of infographics is related to the design, appeal, comprehension and retention. On the other hand, infographics content can be categorized into three: introduction, main event and conclusion. The introductory aspect seeks to introduce the topic of the infographics to the reader. This includes a couple of data visualization that helps in establishing formidable groundwork.

Arum (2012) underscores the importance of the content of the main event or possibly the body of infographics. The main event or body of infographics is predominated with visuals whereas 
the concluding section drives readers to the end of the entire display by wrapping up the intended message.

The knowledge aspect of infographics entails the display of facts and deduction from the content. It includes emphasizing relevant content in order to initiate easy deduction. As one of the predominantly used contemporary learning approaches, infographics allow information to be presented in different visual forms (Williams, 2002). Their type or format has contributed immensely to their usage over time.

\section{Infographics Formats}

In recent times, infographics as a term have become more like articles or speeches than just mere charts. The purpose of these visual images (infographics) can be grouped into three main objectives similar to that of public speaking: to inform, persuade an audience and entertain.

In relation to their formats, Lankow, Ritchie \& Crooks (2012) submits that there are three types of infographics: static, motion, and interactive. David and Quinn (2014) on the other hand categorized the formats into static and dynamic. They added that the dynamic format allows for interactivity.

Shafipoor et al. (2016) extend their categorization into four main classes: static, dynamic, interactive and physical. Shafipoor's et al. (2016) physical infographics hinge on threedimensionality although they agree with Lankow et al. (2012) that both motion and dynamic infographics centre on animation despite their different captions. Yildirim (2016) captures the formats under three main headings: interactive, semi-interactive and non-interactive.

Elsewhere, Al-Mohammadi (2017) simplified the formats into static and motion graphics. AlMohammadi maintains that static infographics include visuals that are usually printed or distributed over the internet as explanatory tools. In sampling the views on the usefulness of animated infographics in the teaching and learning of Biology, Teixeira, Paiva, and Moreira (2017), submit that infographics generally fall under two main formats: static and animated; an opinion Hassan (2016) holds.

Considering the generic attempt to categorize the formats of infographics, it appears these formats can be brought under two main headings: static and animated. Also known as noninteractive, information display in static infographics appears fixed and only has one-way interaction. It is characterized by only viewing and reading user activity. The display output for static infographics includes still images, which narrate a story.

Unlike static infographics, their animated counterpart possesses animated or moving text and images, which are occasionally accompanied by sound. These animated infographics may optionally come with some interactivity where users would have options to click, search for specific data, shape displayed content and also choose which information to access and visualize.

\section{Infographics in Teaching and Learning}

To improve learning and knowledge retention, the frequent use of information visualization has become a frequently used phenomenon. Data visualization includes the use of graphical 
illustrations to communicate effectively relationships between ideas and facts. A more recent and popular genre of information visualization that supports learning is infographics.

These information visualization tools (infographics) are not bound to one particular area but cut across a spectrum of diverse fields such as science, business, education, to mention but few. This research, however, considers their usage in the circles of classroom pedagogy. Coleman (2010) conducted his research to find out the extent to which primary level schoolteachers use charts in their educational practices at Alabama University in the USA. Using descriptive design and questionnaire as his data collection tool to reach desired results. Results showed an increase in teachers' usage of charts, which included most educational practices. Charts, which are typical examples of static infographics proved viable as an instructional tool in their study.

In the fall semester of (2015-2016) at the Near East University, Kocakoyun, Ozdaml, Sahin and Akdag evaluated the views about infographics prepared for anatomy lessons. Per their findings, Kocacoyun and his colleagues recommended that similar studies could be conducted in other courses. Nonetheless, Kocakoyun's et al (2016) study failed to clarify the infographics format they adopted for the study. Although a greater percentage of their respondents showed greater interest in infographics their responses only adds to the numerous ones submitted by their colleagues in the Science Technology Engineering and Mathematics STEM fraternity.

Using a randomized controlled study with 27 engineering undergraduate students, Lyra, Isotani, Reis, Marques, Pedro \& Jaques (2016) investigated the effectiveness of using infographics in learning vis-à-vis conventional instructional materials (graphics + text). Their research sought to bridge a gap in pedagogical issues with infographics by looking at individual factors that may interfere with how students perceive and retain learning materials. Although their results reveal a considerate satisfaction with students' interaction with infographics than the (graphics + text) at the post-test stage of evaluation, the researchers were quiet on the format of infographics they adopted for the study making it cumbersome to ascertain whether similar results could be realized, should the research be replicated elsewhere with the same variables present.

In 2016, Yildirim, an assistant professor at Ataturk University, sought the views of learners on infographics used for educational purposes and the place of infographics among learning preferences using an instant case study design, of students of the Department of Computer Education and Instructional Technology in the said university. Adapting Likert-type questions, Yildirim (2016) tailored his survey for his topic under the following: Informativeness, Selection Preferences, Sharing, Basic Presentation Structure, and Retention-Memorability. With regards to the order of preference of infographics types, Yildirim's respondents rated interactive (animated) infographics over other available options. This preference rate may be as a result of the background of the learners; an assertion Yildirim (2016) agrees to. Will the same choice be merited with learners who may not have a very high computer literacy background similar to Yildirim's?

To improve the retention and easy assimilation of concepts in Biology, Bellei, Welch, Pryor \& Katheesan (2016) employed a collaborative approach by engaging an Immunology and a design lecturer in producing animated infographics for immunology teaching. This Design Thinking approach saw a combination of both static and animated infographics over a period of eight (8) weeks to achieve the intended results: better comprehension. Although learners claimed satisfaction with the visual intervention tool (infographics), the study was aimed at 
finding a cost-effective approach of producing animations for immunology lessons and not necessarily the most effective infographics format that may be the magic wand in achieving similar results.

In teaching complex subjects in science, Hassan (2016) conducted a study for the desired infographics design that would play a supportive role in teaching and learning. He predicts that the creation of an infographic using the animated format would be more effective in communicating a complex science subject that involves spatial and temporal data.

Somewhere in the mid of 2017, Lievemaa studied the pros and cons of animated infographics in educational publishing. His action research was geared towards the production of three practical animated infographics for e-Oppi Oy, a digital educational publishing company in Finland. One key observation is that Lievemaa's animations on some selected topics for e-Oppi Oy were not tested on learners, thereby creating a gap in ascertaining whether animated infographics alone stand a better chance in enhancing comprehension amongst learners.

In two separate schools in Canada; Queen's and Ryerson University, Matrix and Hodson (2014) reported on two case studies where students from these universities were tasked to produce infographics on various themes. Students posted their work online on Learning Management System (LMS) and public blogs respectively for peer assessment and critique. Their research was subjective to the creation of the information visualization (infographics) proficiency by learners. Their findings revealed that the use of infographics help students to build critical faculties needed to understand complex online communication and commercial systems. Despite this evaluation, the research focused on the creation process and not necessarily the learning outcome. This and many other identified gaps identified in the use of infographics in the circles of academia have informed the need to research on the current infographics format being used in the Visual Art classroom at KNUST SHS as well as discuss its accompanying effects.

\section{METHODOLOGY}

This study adopted the case study strategy with interviews as data collection instruments. The study was carried out in the Kumasi Metropolis in the Ashanti region of Ghana. Ghana Education Service (GES) records reveal that among the 89 public Senior High Schools in the Ashanti Region out of which 42 schools offer Visual Art, only 18 are located in the Kumasi Metropolis of which KNUST falls within the bracket of schools that offer Visual Art as a programme of study.

KNUST SHS was conveniently sampled on the premise of proximity and easy accessibility. On the basis of validity and appropriateness, the Visual Art Department became the focal point for the study. The said department had a total population of 160 students and 5 teachers. Out of the 5 teachers, 4 were accessible representing $80 \%$ of the total number. The teachers were purposively and conveniently sampled because they match the needed characteristics for the study (Christensen et al. 2015).

A pilot test was conducted in order to authenticate the research tool (interview guide), refine and further develop the instrument by examining the degree of observer bias, framing of questions and collection of background data. This enabled the researcher room to restructure 
the questions for easier comprehension and answering by the respondents. All the five ethical considerations proposed by Miles and Huberman (1994) were conscientiously adhered to in order to ensure participants' privacy, confidentiality and anonymity.

\section{PHILOSOPHICAL UNDERPINNINGS AND RESEARCH PARADIGM}

The research process has three major dimensions: ontology, epistemology and methodology (TerreBlanche and Durrheim, 1999). Whiles Crotty (1998) explains ontology as the study of being, Scotland (2012) adds that ontological assumptions are mostly hinged on what constitutes reality. Epistemology, on the other hand, is associated with the nature and forms of knowledge (Cohen et al., 2007). Epistemological assumptions constitute the creation, acquisition and communication of knowledge. In his view, Creswell (2003) further expanded these philosophical assumptions by adding axiology (the role of values in the research) and rhetoric (the language of research).

Every paradigm finds its grounds on its own ontological and epistemological assumptions (Scotland, 2012). According to Scotland (2012), what accounts for the different assumptions of reality and knowledge underpinning any study is the differences in ontological and epistemological views. These differences, however, reflect on the methodology and methods adapted from that study. Methodological assumptions are concerned with the strategy or plan of actions that informs the choice and use of a particular method (Crotty, 1998). The methodology takes into keen consideration why, what, where, when and how data is collected and analyzed. How the inquirer goes about finding what is believed is one key feature under Methodology as a research paradigm. According to Grix (2004), it is impossible to conduct any form of research without implicitly committing to ontological and epistemological positions.

It is refreshing to state that this study stems from an ontological stance. According to Creswell (2003), as cited in Moustakas (1994), an ontological stance features the presentation of different perspectives from individuals in a study as well as considering evidence of multiple realities from multiple quotes. This study, however, sampled the different views of the respondents (Visual Art Teachers) on the phenomenon understudied (infographics).

In most qualitative studies, four main worldviews are likely to be adopted by the inquirers. These paradigms or worldviews are post-positivism, constructivism, advocacy/participatory, and pragmatism (Creswell, 2003). This study, however, falls within the brackets of advocacy/participatory. The ideology of advocacy/participatory paradigm hinges on an action agenda to effect change in participants' lives, places of work or even in the inquirer's life. Furthermore, it is also concerned with the change in practice and limits the constraints in media, language, work procedures in educational settings (Kemmis and Wilkinson,1998). Juxtaposing this paradigm to the current study, it is obvious that the study sought to examine efficient and effective procedures that involve the delivery of instructional content in the Visual Art classroom.

\section{PRESENTATION AND DISCUSSIONS OF RESULTS}

\section{Demographic Characteristics of Respondents (Visual Art Teachers)}


Four male teachers participated in this study. The first teacher (T1) has taught in the Visual Art department for a period of 7 years. The second (T2) has taught for 13 years, whiles the third (T3) and fourth (T4) interviewees have taught for 14 and 8 years respectively.

The data gathered from the interview were categorized into analytic codes. These codes were obtained from the qualitative description of responses from the teachers.

After coding the raw data transcribed from the interview, the following themes became prevalent: teaching and learning materials, perception and inaccessibility. These themes would form the basis for the discussion of the accrued data from the respondents.

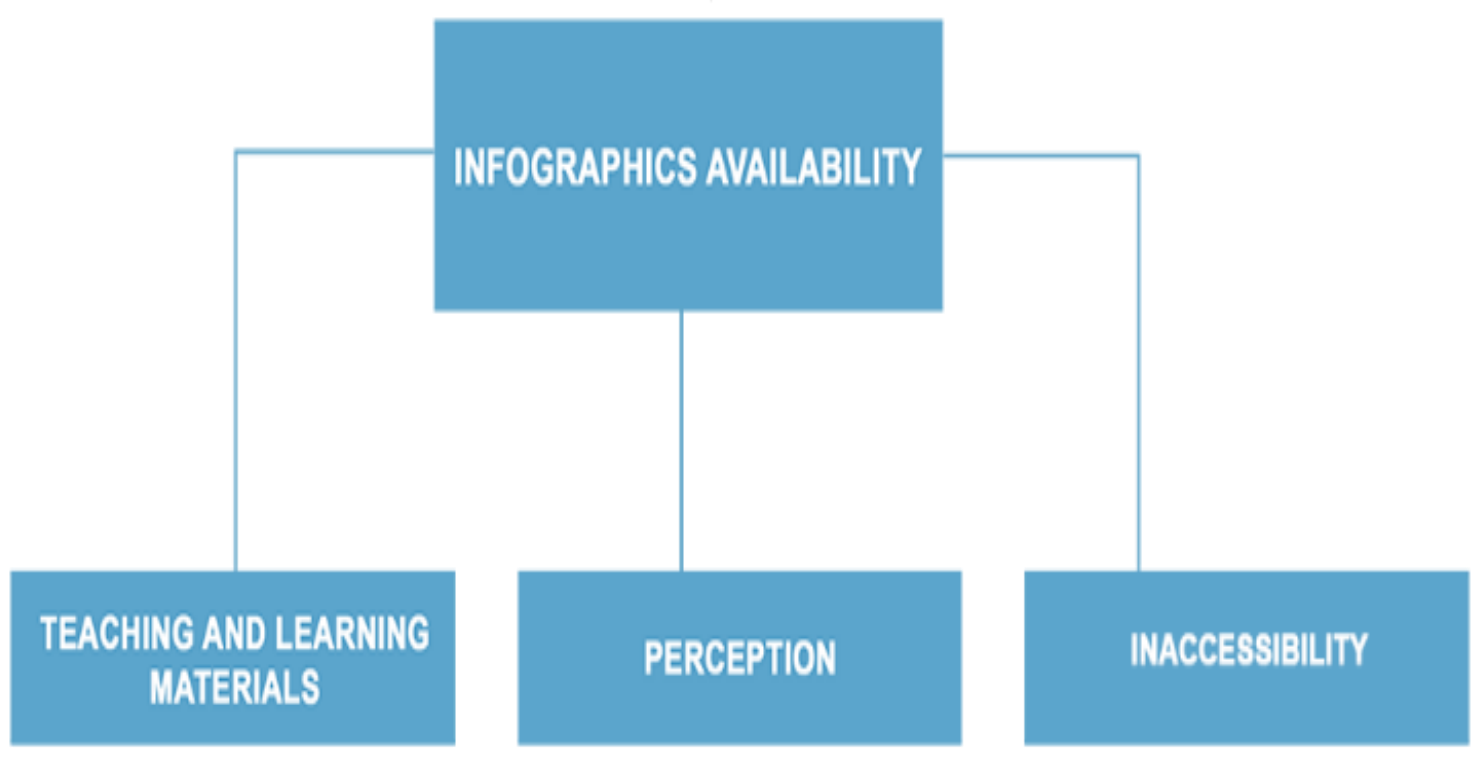

Figure 2: Themes generated from views of the respondents on the availability of infographics

Source: Researchers' construct

\section{INFOGRAPHICS AVAILABILITY}

\section{Theme 1: Teaching and Learning materials}

Teaching and Learning Materials (TLMs) in this context refers to the instructional materials available for the tuition of Visual Art subjects. Whiles all the teachers would prefer teaching with both text and illustrations, their submissions revealed the absence of animated infographics as a TLM in the Visual Art classroom.

Although several topics in the Visual Art syllabus could better be taught with animated infographics, textbook illustrations were the readily available ones (Opoku-Asare et al., 2014).

$>$ “...because there are no animations, all static in the book most teachers don't even teach certain topics, so students don't even know that it's part of the syllabus" (T1 interviewee) 
$>$ "To get the materials to teach the students is not there so if there is an animated version for them to even watch it will even attract them or encourage them to improve upon their creative skills". (T2 interviewee)

The statements by (T1 and T2) indicates that the Visual Art classroom lacks animated videos, hence teaching with traditional tools such as textbooks has become the major means through which Visual Art teachers instruct their students. According to Kember (1997), using animations in teaching and learning facilitates Student-Centered Learning (SCL) and the understanding of concepts by learners. In the context of this study, Visual Art students are deprived of the rich experience and advantages that accompany learning with animated videos. Also, if certain areas of the syllabus are left uncovered because of the unavailability of an alternative or supportive instructional aid such as animated infographics then teaching and learning in the Visual Art classroom needs serious attention.

Stemming from literature, Gill (2006) indicates that a technological learning environment rewards learning difficulties. As revealed from the interview, there is no technological environment in the Visual Art classroom of KNUST SHS. Teachers are left to the mercy of conventional instructional aids such as textbooks. T2 and T3 bemoaned the scarce material resource in teaching Visual Arts subjects.

$>$ 'We don't have much teaching aids materials that's why most often we stick to the textbooks" (T2)

$>$ "Looking even into Visual Arts subjects themselves, we do have a very big problem. Sometimes the materials are not readily available, as I've already stated, sometimes teachers would have to comb for the material themselves" (T3).

From the submissions of (T2, T3) the unavailability of alternative TLMs is a matter of concern. This implies that teachers would have to improvise to ensure the delivery of instruction and completion of the syllabus. However, such improvisation cannot fully be trusted since certain vital concepts might not be fully attended to.

Although some writers have published a few textbooks and pamphlets to support the teaching and learning of Visual Art, the credibility of these educational materials are questionable. From the interview, it was revealed that the only GES approved textbook for the Visual Arts was written as far back as 1994, hence other Visual Art textbooks on the market cannot be hundred percent trustworthy. T3 brings out this exposé and throws caution to the wind.

$>$ "Apart from GKA there is no material and I repeat no material for other areas, which has been produced by the government. So teachers have to source for their own information from wherever they can get them and you can't rely on pamphlets". (T3)

Chepchieng (1995) shares that the availability and quality of textbooks contribute to the relative achievements in senior high schools. In the context of this study, the quality of instruction in the Visual classroom is comprised of teachers who would have to always improvise to ensure the delivery of instruction. This, therefore, calls for the production of alternative teaching and learning material (animated infographics) to augment the available ones. In probing further into the absence of animated infographics in the Visual Art classroom, it was discovered that the 
perception and attitude of the head of the school towards the Visual Art programme contribute to this absence.

\section{Theme 2: Perception}

Perception, as a theme in the context of this study, is the way the Visual Art programme is seen, understood and interpreted by senior high schools' administrators. As revealed by DeGraft-Yankson (2010), Evans-Solomon and Opoku-Asare (2011) the general attitude and perception towards Visual Arts education in Ghana is one of greater concern. The teachers interviewed in this study always alluded to greater attention being given to the sciences in terms of teaching and learning materials and any other educational logistics that would ensure the success of the General Science programme. Comments by $(\mathrm{T} 1, \mathrm{~T} 2)$ reveal this assertion.

$>$ "Everybody thinks science is driving the world so when they say Science Oh! (Exclaims) they have a science laboratory, they have this, they have that. When it comes to the other areas, we are lacking these things and I think these things are making or giving us lots of problems". (T1 interviewee)

$>$ "They give the better one to the Sciences, Look at the nature of the studio let me take you to the science laboratory, and look at the nature of the.... so the perception, right from the top they have neglected us" (T2)

Despite their willingness to abreast their teaching methodology with other instructional aids such as videos, it appears that the perception and attitude of some heads of second cycle institutions as revealed by DeGraft-Yankson (2010) have played a pivotal role in why the Visual Art programme remains under-resourced with innovative educational technologies.

In a similar study, DeGraft-Yankson (2010) indicated that a comment from one of his interviewees (a headmaster) revealed his unwillingness to support the integration of technology (ICT) and technological tools by Visual Art teachers. The situation is the same as that of KNUST SHS where this study was conducted. What this implies is that the unavailability of animated videos and over-reliance on conventional teaching and learning aids is a result of the zero attention given to the Visual Art programmes by senior high school administrators. So the absence of animated videos has little to do with the Visual Art teachers but an attitudinal problem on the part of school heads towards Visual Art.

There is, therefore, the need to discard the erroneous impression held by some heads of Senior High Schools that aside from General Science other programmes such as the Visual Arts should be relegated to the background. Aside from this erroneous perception, accessibility to facilities that support innovative teaching is one of the reasons why the Visual Art classroom remained technologically bankrupt with animated infographics.

\section{Theme 3: Inaccessibility}

In this section of the study, inaccessibility translates into the difficulty in getting resources to aid the instruction of Visual Art subjects. The success in the level of knowledge acquired by learners depends largely on certain parameters. These include the learning objectives and activities, opportunity for critical reflection, availability and accessibility of resources (Pelleth 2010). With much advocacy to integrate Information Communication Technology (ICT) and multimedia tools with their traditional ones by DeGraft-Yankson (2010), the KNUST - Visual 
Art story appears out of the picture. Interestingly, the case school is well-resourced with an ICT lab, nonetheless, access to the facility is only permitted to ICT instructors and ICT lessons. T4 reported that the denial and inability to make judicious use of the computers to facilitate teaching and learning of Visual Art subjects contributes to the absence of teaching with videos (animated infographics).

D "I will talk about facilities. If you come to this school, for instance, we have the ICT lab. That place is being restricted for ICT lessons alone. If you don't teach ICT you can't go there..."

As revealed by (T4) the ardent use of only textbooks to teach is a result of restrictive measures put in place that denies Visual Art teachers the opportunity of using facilities that support innovative teaching and learning. According to the Cognitive Theory of Multimedia Learning (CTML), students are said to learn better when auditory narration sync with corresponding diagrams. In this study, these restrictive measures of using the ICT lab limits learning to black and white textbook text and illustrations. This may not augur well for students who are auditory learners.

It is worthy of note that these findings from the individualistic opinions expressed by the interviewed teachers on the non-availability of alternative TLMs such as animated infographics in the Visual Art classroom, buttresses the ontological stance adapted in this study where the nature of reality (infographics) was examined by a conscientious procedure of questioning.

\section{EFFECTIVENESS OF AVAILABLE INFOGRAPHICS FORMAT}

Having realized the available infographics used in the Visual Art classroom, it became necessary to consider how effective this format has been in providing instruction to learners. This was in consonance with answering the second research question of the study. Two major themes evolved - difficulty and acceptability.

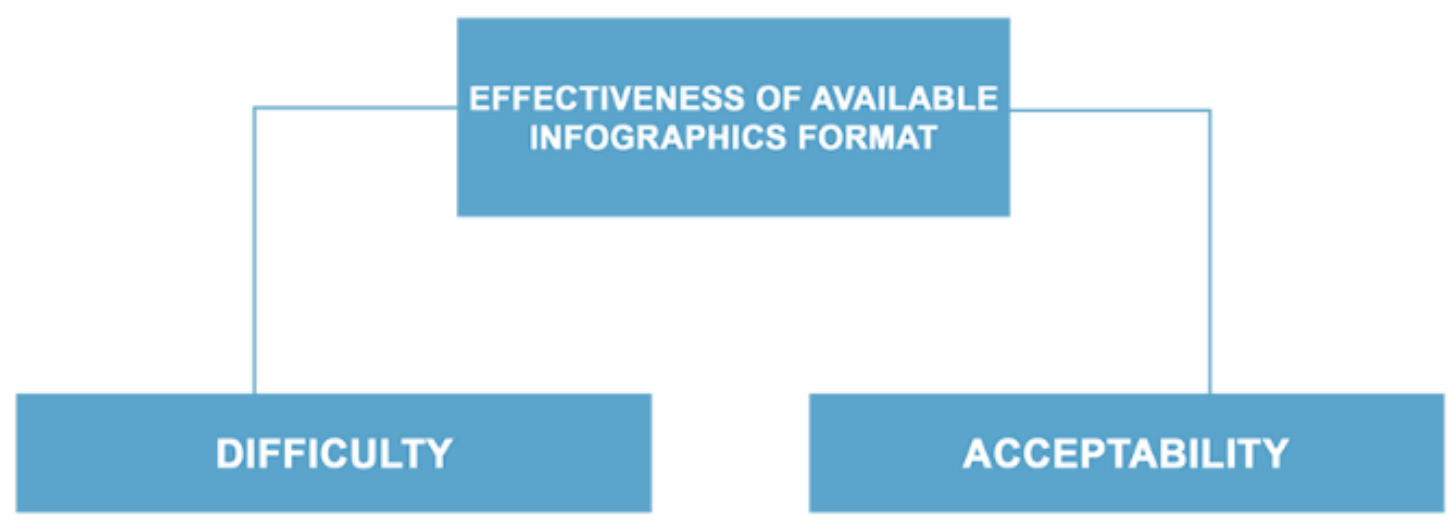

Figure 3: Themes generated from questions asked on the effectiveness of available infographics format

Source: Researchers' construct 


\section{Theme 1: Difficulty}

Contextually, difficulty as a theme in this study is the challenging nature of providing instruction to Visual Art students without animated infographics. Although the findings reveal the presence of static infographics in the Visual Art classroom, the success story has been a blurred one. Most of the views expressed by the interviewees (teachers) translate into the difficulty that accompanies teaching without animated illustrations.

The 21st-century student lives in an auditory, visual and kinesthetic world, hence, there is a clarion call by researchers such as Shafipoor et al. (2016) to augment today's teaching with current instructional methods and media. Nonetheless, the Visual Art classroom lacks alternative instructional media such as animated videos making teaching and learning cumbersome and "abstract" especially in topics where the still illustrations have proved ineffective.

For most of the teachers interviewed, their views portrayed dissatisfaction with the overreliance on only conventional tools for teaching. According to (T1), static illustrations on topics that involve a stepwise procedure of executing a project or design are hurriedly skipped to the finished stage. This he believes deprives students of grasping some technicalities that are difficult to illustrate. He however alludes to animated infographics as providing the alternative solution of in-depth presentation of facts.

This assertion by $\mathrm{T} 1$ embraces the advocacy/participatory paradigm which is concerned with a change in practice and limit the constraints in media, language, work procedures in educational settings (Kemmis and Wilkinson,1998)

$>$ "Well, the STATIC does not normally depict processes. I believe if it is animated definitely whatever that goes into the production you will see it but the static if the person feels that the next process is even difficult to illustrate, he will jump it and all of a sudden that's the finished work". (T1 interviewee)

On the other hand, students go through the arduous task of memorizing concepts for the sake of passing an exam without necessary understanding these concepts. In his submission, (T2) explained that most of their teaching is done in "abstract". He attributes this abstract teaching to the unavailability of animated infographics.

$>$ Over here we are not having it (referring to animation) so it becomes something like an abstract thing that we do. They memorize it and at the end of the day they go and meet any application question because they are not introduced to that aspect it becomes difficult for them". (T2 interviewee)

Interpreting T2's comments, the researcher would say that the absence of animated infographics has resulted in difficulty in teaching and learning by teachers and students respectively. If the overall objective of the Visual Art programme goes beyond passing an exam but engaging students with the holistic acquisition of skills, then teaching students in abstract defeats this objective of the Curriculum Review and Development Division (CRDD) of Ghana. T4 adds that students even find it difficult in grasping simple concepts due to the absence of motion pictures. 
$>$ “...Sometimes you have to talk and talk and talk, to explain a little thing but when the pictures are there when these things are in motion, the students can just watch and grasp the concept without you talking sometimes". (T4 interviewee)

Drawing an inference from T4's statement, the researcher can conclude that so much time is consumed during instructional hours to drum home simple concepts. This he (T4) alludes to making teaching and learning in the Visual Art classroom cumbersome.

$>$ The educational system as we have it now is having a lot of problems in respect to the teaching of Visual Art subjects in general; I'm not limiting any aspect of it and it makes teaching and learning very difficult. (T4 interviewee)

\section{Theme 2: Acceptability}

Acceptability here means the high rate of expectancy and readiness exhibited by the teachers for an alternative or complementary instructional aid. Having stated their difficulty during instructional hours with the static textbook illustrations, they (teachers) embraced the idea of getting a complementary instructional aid (animated infographics) as suggested by the researcher. "It's not about the teachers not ready to use it because if you want the people who have the technical know-how, we have them better in an area but then the administrative misconception about the course and the department makes it difficult to sometimes reach the target that you want to reach", a comment by one of the art teachers (T4). Comments such as the aforementioned (T4) revealed the readiness to use these animations vis-à-vis the traditional teaching and learning materials. The passion and enthusiasm that was demonstrated by the teachers when the research area was introduced to them were indicative of the fact that they had lived in expectancy for long and had anticipated a change in instructional delivery. This is in line with the advocacy/participatory paradigm, which suggests that instructional delivery would experience a facelift when there is a change in practice and constraints in the use of media in educational settings are limited.

The ICT Policy statement by the Ghanaian government on education shows her commitment to promoting technical and vocational training (ICT4AD Policy, 2003). If indeed the Visual Art programme falls within the brackets of technical and vocational training then there is a need for a comprehensive overview, attention and support to the Visual Art programme by the government by putting in place mechanisms and structures that would support innovative teaching in the Visual Art classroom.

\section{CONCLUSIONS}

In this technologically advancing age, the teaching and learning process has become interesting, effective, enjoyable and memorable when teaching and learning materials possess some innovative traits. From an educational stance, the prowess of animation as a pedagogical tool cannot be underestimated especially when aligned with the objectives of the educational curriculum.

Citing from the study, animated infographics appear to be a bridge-builder and an alternative instructional tool that could help in addressing the difficulty faced by Visual Art teachers in explaining both complex and simple concepts to their students. Its potential prowess could 
augment instructional delivery, thereby creating a more creative environment and effecting change in the lives of both instructors and recipients, an assertion that answers to the advocacy/participatory paradigm.

\section{SUMMARY OF FINDINGS}

- The only available infographics format available to the Visual Art teachers of KNUST SHS is the static version. Textbook and manila card illustrations fall under this category of infographics.

- The negative perception of some heads of Senior High Schools with KNUST SHS with no exception has contributed to the absence of innovative instructional tools such as animated infographics in the Visual Art classroom.

- Teaching and learning especially practical content is said to be an arduous task. Teachers are left with no option but to improvise.

- Some topics of the Visual Art curriculum that could be best taught with interactive instructional teaching such as animated infographics are deliberately skipped by the teachers because static images only force students to think in abstract.

\section{RECOMMENDATIONS}

i. It is important to note that curriculum planners, policymakers and other stakeholders in education should consider liaising with instructional designers to produce animations as supplementary instructional aids alongside traditional teaching and learning materials.

ii. The professional development of teachers in technology usage and pedagogical knowledge should be an ongoing process. Teachers should be abreast with new evolving roles and explore pedagogical options in bringing instructions to their students.

iii. This study could be replicated in separate schools to compare results. Using KNUST SHS as a case study limits generalization of the findings, hence a wider population could be considered.

\section{Suggestion for Future Research}

Among other measures, a one-year academic Performance Assessment Procedures (PAP) could be conducted on the effectiveness of incorporating animated infographics in the Visual Art classroom. 


\section{REFERENCES}

Bellei, M., Welch, P., Pryor, S., \& Katheesan, N., 2016, 'A Cost-Effective Approach to Producing Animated Infographics for Immunology Teaching', Journal of Microbiology and Biology Education, 17(3): 477-479.

Creswell, Christensen, L., Johnson, R., \& Turner, L.A., 2015, Research Methods, Design and Analysis, 12th edn., Pearson, Edinburgh, England.

Creswell, J. W., 2003, 'Research design: Qualitative, quantitative, and mixed methods approach', 2nd edn... Thousand Oaks, CA: Sage.

Crotty, M., 1989, The foundations of social research: Meaning and perspectives in the research process, London, Sage.

DeGraft-Yankson, P., 2010, 'Framework development for integrating information and communication technologies into the Ghanaian senior high school visual art curriculum', PhD thesis, Dept. of General Art Studies, Kwame Nkrumah University of Science and Technology.

Evans-Solomon, F., Opoku-Asare, N. A., 2011, 'Girls' motivation, participation and preference for visual arts subjects in four senior high schools in Central region, Ghana', Journal of Science and Technology 31(3), 118-128.

Gill, G., 1995, Assessing student-centred Courses. Oxford Centre for Staff Learning and Development.

Grix, J. 2004, The foundations of research, London, Palgrave Macmillan.

Hassan, H.G., 2016, 'Designing Infographics to support teaching complex science subject: A comparison between static and animated Infographics', Master's thesis, Iowa State University.

https://www.researchgate.net/publication/317689647

Kember, D., 1997, 'A reconceptualisation of the research into university academics conceptions of teaching, Learning and Instruction, 7(3), 255-275.

Kemmis, S., \& Wilkinson, M. (1998), 'Participatory action research and the study of practice'. In B. Atweh, S. Kemmis, \& P. Weeks (Eds.), 'Action research in practice: Partnerships for social justice in education', (pp. 21-36). New York, Routledge.

Kocakoyun, S., Ozdaml, F., Sahin, T., \& Akdag, S., 2016, 'Statistical reasoning of the impact of infographics on education', 12th International Conference on Application of Fuzzy Systems and Soft Computing, ICAFS 2016, 29-30 August 2016, Vienna, Austria.

Lamb, G. R., Polman, J. L., Newman, A., \& Smith, C. G., 2014, 'Science news infographics: Teaching students to gather, interpret, and present information graphically'. The Science Teacher, 81(3), 29.

Lankow, J., Ritchie, J., \& Crooks, R., 2012, Infographics: The power of visual storytelling, John Wiley \& Sons, Inc., Hoboken, N. J.

Lyra, K. T., Isotani, S., Reis, R.C.D., Marques, L.B., Pedro, L.Z., Jaques, P.A., et al., 2016, 'Infographics or Graphics+Text: Which Material is Best for Robust Learning?' Proceedings of the IEEE International Conference on Advanced Learning Technologies (ICALT),

Noh, S.M. \& Son, J., 2015. 'The Effect of Physics Instruction Using Infographics Based on Visual Thinking in High School', Journal of The Korean Association for Science Education, 35(3), pp.477-485. 
Opoku-Asare, A. N., Agbenatoe, G.W., \& deGraft-Johnson, K. G., 2014, 'Instructional Strategies, Institutional Support and Student Achievement in General Knowledge in Art: Implications for Visual Arts Education in Ghana', Journal of Education and Practice, Vol.5 (21)

Roy, S., 2009, The Anatomy of an Infographic: 5 Steps to create a powerful visual, viewed on 6 November 2017, from http://spyrestudios.com/the-anatomy-of-an-infographic-5steps-to-create-a-powerful-visual/

Scotland, J. 2012, 'Exploring the Philosophical Underpinnings of Research: Relating Ontology and Epistemology to the Methodology and Methods of the Scientific, Interpretive, and Critical Research Paradigms', English Language Teaching, Vol. 5(9).

Shafipoor, M., Sarayloo, R., \& Shafipoor, A., 2016, 'Infographic (information graphic); A tool for increasing the efficiency of teaching and learning processes', International Academic Journal of Innovative Research, Vol. 3, No. 4, 2016, pp. 39-45.

Siaw, O. A., \& Nortey, S., 2011, 'Teaching and Learning of Visual Arts in Senior High Schools in Ghana', Journal of Education and Practice 2(4), 111-113.

Siaw, O. A., 2009, 'A comparative study of teaching and learning processes of the visual arts in selected senior high schools in urban and rural settings in Ashanti region, Ghana', Master's thesis, Dept. of General Art Studies, Kwame Nkrumah University of Science and Technology.

Smiciklas, M., 2012, The power of infographics: Using Pictures to Communicate and Connect with Your Audiences, Pearson Education, Inc.

Teixeira, A., Paiva, J.C., \& Moreira, L., 2017, 'Views on the usefulness of animated infographics for learning and teaching biology', viewed on 22 October 2017 from

TerreBlanche, M., \& Durrheim, K. 1999, Research in practice. Cape Town, UCT Press.

Warmann, J., 2016, 'Using animation as an intervention for teaching and learning senior high school geometry in mathematics', Master's thesis, Dept. of Communication Design, Kwame Nkrumah University of Science and Technology.

Yildirim, S., 2016, Infographics for Educational Purposes: Their Structure, Properties and Reader Approaches, The Turkish Online Journal of Educational Technology, 15(3). 